\title{
The Impact of Human Milk Feeding on Long-Term Risk of Obesity and Cardiovascular Disease
}

\author{
Atul Singhal ${ }^{1,2}$
}

B EYOND JUST MEETING NUTRITIONAL REQUIREMENTS, nutrition during infancy is linked to disease later in life, a concept known as "the developmental origins of health and disease." As early as the 1930s, study in rodents demonstrated that early calorie restriction increased the life span by $35 \%$ and reduced the incidence of tumors, kidney disease, vascular calcification, and chronic pneumonia. ${ }^{1}$ In the $1960 \mathrm{~s}$, studies in rats showed that early nutrition during the first 3 weeks had a life-long impact on body size; rats that received less milk during this time continued to weigh less throughout life compared with rats that received more milk. ${ }^{2}$ Further evidence for nutritional programming came from studies in baboons, which showed that overfeeding during infancy increased the tendency for obesity in adulthood. ${ }^{3}$

One of the first studies to demonstrate nutritional programming in humans showed that rapid weight gain from as early as the first 6 weeks of life was associated with obesity at 8 years of age. ${ }^{4}$ Beginning in the late 1980 s, observational studies linking low birth weight with later cardiovascular risk factors and diabetes shifted focus to nutrition during the fetal period, resulting in the "fetal origins of adult disease" hypothesis. ${ }^{5}$ Subsequent studies have suggested that, although a high-quality maternal diet can prevent infants born small for gestational age (SGA) and low birth weight, dietary supplementation during pregnancy may not affect the offspring's risk of obesity and cardiovascular disease. ${ }^{6-9}$ Other studies suggest prepregnancy obesity and maternal weight gain are associated with obesity in the offspring; however, there has been no convincing evidence of a causal effect of these factors on offspring obesity. ${ }^{10-12}$

There have been several systematic reviews supporting the positive effects of breastfeeding on cardiovascular risk factors, such as obesity and type 2 diabetes. ${ }^{13,14}$ Experimental trials in preterm infants assigned to donor human milk or formula demonstrated the beneficial effects of human milk on blood pressure, cholesterol, obesity, and insulin resistance. ${ }^{15-18}$ One possible explanation for the benefits of human milk on cardiovascular risk may be the slower growth of infants receiving breast milk versus those receiving formula (i.e., the growth acceleration hypothesis). ${ }^{19}$ Human milk has lower energy and protein content than formula, resulting in slower weight gain during infancy with human milk versus formula. Faster infant growth has been associated with later obesity in many studies, including five randomized trials. ${ }^{19}$ A randomized trial of high nutrient intake in term SGA infants showed that infants fed enriched formula had significantly higher diastolic blood pressure and fat mass at 6-8 years compared with those fed standard formula. ${ }^{20,21} \mathrm{Simi}-$ larly, a multicenter randomized trial by the European Childhood Obesity Group reported a significantly higher body mass index and a 2.4 times greater risk of becoming obese at 6 years of age in infants who had been fed a highprotein formula versus those fed a low-protein formula in infancy. ${ }^{22}$ It has been hypothesized that accelerated growth in infancy may result in hormonal changes that program a higher set point for appetite, leading to higher food intake throughout life. ${ }^{23}$ Bottle-fed infants may be less likely to regulate milk intake or appetite later in infancy; infants receiving human milk from a bottle were $67 \%$ less likely to have a high satiety response. ${ }^{24}$

In summary, there is strong evidence supporting the benefits of breastfeeding and human milk consumption during infancy for long-term cardiovascular health. These benefits may be related to the slower early growth of infants receiving human milk or lower-protein formulas versus those fed standard formulas. Preventative strategies, such as promoting breastfeeding, reducing the protein content of formula, avoiding overnutrition, and encouraging responsive bottle feeding (i.e., recognizing feeding cues), may help to slow the rate of weight gain in infancy and reduce the long-term burden of cardiovascular disease.

\section{Disclosure Statement}

No competing financial interests exist.

\section{References}

1. McCay CM. Is longevity compatible with optimum growth? Science 1933;77:410-411.

2. Widdowson EM, McCance RA. Some effects of accelerating growth. I. General somatic development. Proc $R$ Soc Lond B Biol Sci 1960;152:188-206.

3. Lewis DS, Bertrand HA, McMahan CA, et al. Preweaning food intake influences the adiposity of young adult baboons. J Clin Invest 1986;78:899-905.

\footnotetext{
${ }^{1}$ Institute of Child Health, University College London, London, United Kingdom.

${ }^{2}$ Great Ormond Street Hospital, London, United Kingdom.
}

(C) Atul Singhal, 2019; Published by Mary Ann Liebert, Inc. This Open Access article is distributed under the terms of the Creative Commons License (http://creativecommons.org/licenses/by/4.0), which permits unrestricted use, distribution, and reproduction in any medium, provided the original work is properly cited. 
4. Eid EE. Follow-up study of physical growth of children who had excessive weight gain in first six months of life. $\mathrm{Br}$ Med J 1970;2:74-76.

5. Barker DJ. Fetal origins of coronary heart disease. BMJ 1995;311:171-174.

6. Haider BA, Bhutta ZA. Multiple-micronutrient supplementation for women during pregnancy. Cochrane Database Syst Rev 2015;CD004905.

7. Ota E, Hori H, Mori R, et al. Antenatal dietary education and supplementation to increase energy and protein intake. Cochrane Database Syst Rev 2015;CD000032.

8. Hawkesworth S, Walker CG, Sawo Y, et al. Nutritional supplementation during pregnancy and offspring cardiovascular disease risk in The Gambia. Am J Clin Nutr 2011; 94:1853S-1860S.

9. Fall C. Maternal nutrition: effects on health in the next generation. Indian J Med Res 2009;130:593-599.

10. Patro B, Liber A, Zalewski B, et al. Maternal and paternal body mass index and offspring obesity: A systematic review. Ann Nutr Metab 2013;63:32-41.

11. Yu Z, Han S, Zhu J, et al. Pre-pregnancy body mass index in relation to infant birth weight and offspring overweight/obesity: A systematic review and meta-analysis. PLoS One 2013;8:e61627.

12. Sharp GC, Lawlor DA, Richardson SS. It's the mother!: How assumptions about the causal primacy of maternal effects influence research on the developmental origins of health and disease. Soc Sci Med 2018;213:20-27.

13. Horta BL, Loret de Mola C, Victora CG. Long-term consequences of breastfeeding on cholesterol, obesity, systolic blood pressure and type 2 diabetes: A systematic review and meta-analysis. Acta Paediatr 2015;104:30-37.

14. Patro-Gołąb B, Zalewski BM, Kołodziej M, et al. Nutritional interventions or exposures in infants and children aged up to three years and their effects on subsequent risk of overweight, obesity, and body fat: A systematic review of systematic reviews. Obes Rev 2016;17:1245-1257.

15. Singhal A, Cole TJ, Lucas A. Early nutrition in preterm infants and later blood pressure: Two cohorts after randomised trials. Lancet 2001;357:413-419.
16. Singhal A, Farooqi IS, O'Rahilly S, et al. Early nutrition and leptin concentrations in later life. Am J Clin Nutr 2002; 75:993-999.

17. Singhal A, Fewtrell M, Cole TJ, et al. Low nutrient intake and early growth for later insulin resistance in adolescents born preterm. Lancet 2003;361:1089-1097.

18. Singhal A, Cole TJ, Fewtrell M, et al. Breastmilk feeding and the lipoprotein profile in adolescents born preterm. Lancet 2004;363:1571-1578.

19. Singhal A. Long-term adverse effects of early growth acceleration or catch-up growth. Ann Nutr Metab 2017;70: 236-240.

20. Singhal A, Cole TJ, Fewtrell M, et al. Promotion of faster weight gain in infants born small for gestational age: Is there an adverse effect on later blood pressure? Circulation 2007;115:213-220.

21. Singhal A, Kennedy K, Lanigan J, et al. Nutrition in infancy and long-term risk of obesity: Evidence from 2 randomized controlled trials. Am J Clin Nutr 2010;92: 1133-1144.

22. Weber M, Grote V, Closa-Monasterolo R, et al. Lower protein content in infant formula reduces BMI and obesity risk at school age: Follow-up of a randomized trial. Am J Clin Nutr 2014;99:1041-1051.

23. Widdowson EM, McCance RA. A review: New thoughts on growth. Pediatr Res 1975;9:154-156.

24. Disantis KI, Collins BN, Fisher JO, et al. Do infants fed directly from the breast have improved appetite regulation and slower growth during early childhood compared with infants fed from a bottle? Int J Behav Nutr Phys Act 2011; 8:89.

Address correspondence to: Atul Singhal, $M D, M R C P$ Institute of Child Health

University College London WC1N 1EH London United Kingdom

E-mail: a.singhal@ucl.ac.uk 